\title{
Cürufa Olan Bakır Kayıplarında Farklı Kroze Kullanımının Etkisi
}

\author{
Aydın RÜŞEN ${ }^{* 1}$ \\ ${ }^{1}$ Karamanoğlu Mehmetbey Üniversitesi, Mühendislik Fakültesi, Metalurji ve Malzeme \\ Mühendisliği Bölümü, Karaman
}

Geliş tarihi: 13.04.2017 Kabul tarihi: 31.05 .2017

$\ddot{\mathbf{O z}}$

Bakır işletmelerinde ergitme aşamasında cürufa olan bakır kayıpları sektördeki önemli problemlerden biridir. Bu çalışmada, Eti Bakır İşletmelerinden (EBİ) temin edilen flaş firın cürufu ve flaş fırın matı eşit miktarlarda alınarak farklı oranlarda kolemanit $\left(2 \mathrm{CaO} \cdot 3 \mathrm{~B}_{2} \mathrm{O}_{3} \cdot 5 \mathrm{H}_{2} \mathrm{O}\right)$ ilavesi $(\% 0, \% 2, \% 4$ ve \%6) ile karıştırılıp alumina $\left(\mathrm{Al}_{2} \mathrm{O}_{3}\right)$ krozelerde $1250^{\circ} \mathrm{C}$ 'de ve azot atmosferi altında 2 saat boyunca ergitme deneylerine tabi tutulmuştur. Böylece, alümina kroze (AK) kullanılan deneylerde cürufa olan bakır kaybı oranları gözlemlenmiş ve aynı deneysel koşullarda silika kroze (SK) kullanılarak yapılmış deneylerden elde edilen değerler ile karşılaştırılmıştır. Ayrıca, FactSage programı yardımıyla deneyler sonucunda oluşan cüruflara ait viskozite ile sıvılaşma sıcaklığı değerleri hesaplanmış ve ilk katılaşan faz ortaya çıkarılmıştır. Deneysel bulgular kolemanit ilavesinin flaş fırın cürufuna kaybedilen bakır miktarının her iki tip kroze kullanılması durumda da önemli oranda azaltılabildiğini göstermiştir.

Anahtar Kelimeler: Bakır kaybı, Cüruf, Alumina kroze, Silika kroze, FactSage

\section{Effect of Different Crucible Usage on Copper Losses to Slag}

\begin{abstract}
Copper losses to the slag in the smelting stage are one of the major problems in copper production factories. In this study, flash furnace slag and flash furnace matte provided by Eti Copper Co. (EBI) were melted at $1250^{\circ} \mathrm{C}$ for 2 hours under the nitrogen atmosphere in alumina crucibles with different proportions $(0 \%, 2 \%, 4 \%$ and $6 \%)$ of colemanite $\left(2 \mathrm{CaO} \cdot 3 \mathrm{~B}_{2} \mathrm{O}_{3} \cdot 5 \mathrm{H}_{2} \mathrm{O}\right)$ addition. The amount of the copper losses to slag in alumina crucibles was observed and also compared with the values obtained from the same experimental conditions by using silica crucible. In addition, liquidus temperature and viscosity of the resultant slags were calculated and the first precipitates were revealed by using FactSage model program. According to the results, the level of copper losses to the slag was significantly reduced by the addition of colemanite for both types of the crucible.
\end{abstract}

Keywords: Copper loss, Slag, Alumina crucible, Silica crucible, FactSage

*Sorumlu yazar (Corresponding author): Aydın RÜŞEN, aydinrusen@kmu.edu.tr. 


\section{GíRiş}

Dünya bakır üretiminin büyük kısmı ( \%80) cevherden gerçekleştirilmekte olup, üretim metotları genellikle cevher türüne göre değişiklik göstermektedir. Oksitli cevherlerden bakır üretimi için genellikle hidrometalurjik yöntemler ve sülfürlü cevherlerden bakır üretimi için genellikle pirometalurjik yöntemler tercih edilmektedir. Cevherden pirometalurjik yolla bakır üretiminde flotasyon sonrası yaklaşık \%20 Cu içeriğine sahip konsantre sirasıyla; Ergitme (Smelting) \%45-50 $\mathrm{Cu}-$ Konvertisaj (Converter) \%98-99 Cu - Ateşle Rafinasyon (Fire Refining) - \%99,5 Cu ve Elektrolitik Rafinasyon (Electrorefining) aşamalarından geçerek \%99,99 $\mathrm{Cu}$ ihtiva eden katot levhalar olarak elde edilmektedir. Bakır üretiminde, özellikle ergitme ve konvertisaj aşamalarında oluşan cüruflar içerdikleri bakır oranları sebebiyle oldukça önemli atıklar içerisinde yer almaktadır [1-3].

Bakır üretiminin geri kalan k1smı $(\sim \% 20)$ ise ikincil kaynak olarak değerlendirilen bakır hurdalarından gerçekleşmektedir. Bakır hurdalarının tekrar kullanıma dönüşü ateşle rafinasyonu aşamasından başlamaktadır. Yüksek bakır içerikli hurdalar genellikle blister bakır ve/veya külçe bakır ilavesiyle beraber anot firınına (genellikle Thomas tipi firınlar) yüklenerek flakslaştırıcıların (cüruf yapıcı $\mathrm{SiO}_{2}$ ve/veya $\mathrm{CaCO}_{3}$ ) ilavesiyle rafinasyon işleminden geçirilir. $\mathrm{Bu}$ aşamada oluşan cüruflarda da önemli ölçüde bakır kaybı $(\% 5-10 \mathrm{Cu})$ yaşanmaktadır $[1,4]$.

Gerek birincil gerekse de ikincil bakır üretimi yapan işletmelerin üretim kapasiteleri ve oluşan cüruf miktarları göz önüne alındığında ortaya çıkan cüruflardaki bakır kayıpları sektör için önemli bir problem oluşturmaktadır [5].

\section{2. ÖNCEKİ ÇALIŞMALAR}

Cürufa olan bakır kayıplarını önlemek veya azaltmak için yapılan çalışmalar [3, 6-8] bakır kayıplarının mekaniksel kayıplar ve fizikokimyasal kayıplar olmak üzere iki şekilde gerçekleştiğini göstermektedir. Mekaniksel kayıplar; cüruf içinden geçerek mat bölgesine ulaşmak için yeterince zaman bulamamış veya cürufun viskozitesinin yüksek olmasından dolayı cüruf içinde asılı halde kalan bakır veya mat taneciklerinin oluşturduğu kayıplardır. Fizikokimyasal olarak tanımlanan kayıplar ise iyonize cüruf eriyiği içinde $\mathrm{Cu}^{+}$iyonu olarak bulunan bakırın oluşturduğu kayıplardır. Diğer bir değişle, sülfürlü $\left(\mathrm{Cu}_{2} \mathrm{~S}\right)$ ve oksitli $\left(\mathrm{Cu}_{2} \mathrm{O}\right)$ haldeki bakırın cüruf içindeki çözünürlüğünden ileri gelen kayıplardır.

Bakırın pirometalurjik yolla üretiminde silis $\left(\mathrm{SiO}_{2}\right)$ en yaygın olarak kullanılan flakslaştırıcıdır [2]. 1220-1250 ${ }^{\circ} \mathrm{C}$ civarına 1sitilan bakır ergitme firınlarında; silis ile demir oksit $(\mathrm{FeO})$ birleşerek yoğunluğu düşük fayalit fazını (cüruf) oluşturmakta iken şarj içerisindeki kalkopirit yap1 sayesinde bakır açısından zengin ve daha yoğun bir mat $\left(\mathrm{Cu}_{2} \mathrm{~S}-\mathrm{FeS}\right)$ fazının oluşmasını sağlanır.

Bakır üretiminde, şarjın ergitilmesi sonucunda oluşan mat (veya sistemde oluşan metalik bakır) tanecikleri cüruf içinde aşağı doğru çökerek ayrışmaktadır. Burada cürufun akışkanlığı oldukça önem arz etmektedir. Çünkü cüruf dinlenme bölgesinde ayrışmak için yeterli süreyi bulamayan mat tanecikleri, cürufun alınması sırasında cüruf ile birlikte atılmakta ve mekaniksel bakır kayıplarına yol açmaktadır [3, 8-10]. Bu sebeple bu tür sistemlerde kayıpların azaltılması için cüruf akışkanlığına etki edecek kolemanit gibi flakslaştırıcıların ilavesi yaygın olarak araştırılmakta olan bir konu olarak ortaya çıkmaktadır. Kolemanitin demir-çelik endüstrisinde flaks olarak kullanılması üzerine yapılan çalışmalarda $[11,12]$ kolemanitin cürufun akışkanlığını arttırdığı ve erime sıcaklığını düşürme yönünde etki ettiği görülmüştür. Bakır sektöründe ise ergitme cüruflarından kaynaklanan kayıpları önlemek için kolemanit ilavesi daha önce araştırılmış olan bir konudur. Rusen ve arkadaşları [3, 7, 13] tarafından ergitme cürufları için laboratuvar koşullarında farklı deneysel şartlar altında yapılan çalışmalarda, bakır kayıplarının kolemanit ilavesi ile azaltılabileceği ortaya konmuştur. Bu çalışmalarda, flaş firın cüruflarına kolemanit ilavesi ile bakır kayıplarındaki değişim farklı sürelerde, farklı sıcaklıklarda ve farklı 
atmosferlerde (azot ve belirli k1smi oksijen basıncına sahip atmosferler) araştırılmıştır. Ancak, yapılan deneysel çalışmaların tamamı silika krozeler içerisinde yapıldığından elde edilen sonuçların cürufun silikaya doymuş bölgesi için geçerli olduğu söylenebilir. Ergitme deneylerinin silika dışında farklı krozeler kullanılarak yapılması ile silikaya doymamış bölgeler için cürufa olan bakır kayıplarındaki davranış bu çalışma kapsamında incelenmesi gereken bir konu olarak ele alınmıştır. Bu çalışmada, başlangıç malzemesi olarak EBİ flaş firın cüruf ve matı alınarak, alümina kroze (AK) kullanımının cürufa olan bakır kaybı üzerine etkileri, deneyler neticesinde oluşan nihai cürufların sıvılaşma sıcaklığı ve viskozite özellikleri de dikkate alınarak araştırılmıştır. Ayrıca, kolemanit ilavesi, süre, sıcaklık ve ortam atmosferi gibi değişken parametreleri aynı olan bir sistemde alümina dışında farklı türde (silika kroze; SK) kroze kullanımıyla ortaya çıkan sonuçlar ile karşılaştırılarak irdelenmiştir.

\section{MATERYAL VE METOT}

\subsection{Materyal}

Flaş firın matı ve cürufu: Ülkemizde cevherden bakır üretimi yapan tek işletme olan Eti Bakır İşletmelerinde (EBİ) konsantre haldeki şarjın ergitilerek mat ve cüruf fazlarının oluşturulması amacıyla flaş firın sistemi kullanılmaktadır. $\mathrm{Bu}$ sebeple, deneylerde kullanılmak üzere EBİ'nden flaş firın matı ve cürufu temin edilmiştir. Çizelge 1 'de verilen EBİ flaş fırın matı ve cürufunun kimyasal bileşimi ODTÜ Merkezi Laboratuvarında bulunan İndüktif Çiftleşmiş Plazma-Kütle Spektrometresi (ICP-MS; Perkin Elmer DRC II model), ODTÜ Metalurji ve Malzeme Mühendisliğinde bulunan X-1şını Floresans Spektrometresi (XRF; Bruker S8 Tiger) ve Manyetit Analizörü (SATMAGAN S135) gibi farklı cihazlar yardımıyla belirlenmiştir. Ayrıca, mat ve cüruftaki $\mathrm{Cu}$ içerikleri EBİ Kimya Laboratuvarında yaş kimyasal metot kullanılarak analiz edilmiş ve ICP-MS sonuçları ile paralellik gösterdiği belirlenmiştir.

Çizelge 1'de yer alan bakır analizleri ICP-MS cihazı kullanılarak elde edilmiş olan değerler olup, cüruf ve mat içerisindeki $\mathrm{Cu}$ miktarlarındaki standart sapma sirasiyla $\pm 0,02$ ve $\pm 0,8$ olarak belirlenmiştir. Cüruftaki demir oksit $(\mathrm{FeO})$ miktarı içerisinde yer alan manyetit miktarının SATMAGAN S135 cihazı ile belirlenmesinden sonra toplam demir oranından yola çıkarak hesaplanmıştır.

Çizelge 1. EBİ flaș fırın matı ve cürufunun kimyasal bileșimi

\begin{tabular}{|c|c|c|}
\hline İçerik (\%) & Flaş Fırın Matı & Flaş Fırın Cürufu \\
\hline $\mathrm{Cu}$ & 50,18 & 0,88 \\
$\mathrm{SiO}_{2}$ & - & 36,1 \\
$\mathrm{Fe}_{\mathrm{Toplam}}$ & 27,4 & 36,7 \\
$\mathrm{Fe}_{3} \mathrm{O}_{4}$ & - & 5,3 \\
$\mathrm{FeO}$ & - & 43,9 \\
$\mathrm{CaO}$ & - & 0,6 \\
$\mathrm{Al}_{2} \mathrm{O}_{3}$ & - & 3,2 \\
$\mathrm{~S}$ & 19,8 & 0,8 \\
$\mathrm{Zn}$ & 2,0 & 3,3 \\
\hline
\end{tabular}

Flaş fırın cürufu numunesinin mineralojik yapısı Rigaku D/MAX2200/PC X-1şını difraksiyon (XRD) cihazı kullanılarak elde edilmiştir. 15-85 aralığında $0,02^{\circ}$ sıklığında $\mathrm{CuK} \alpha$ tipi radyasyon ışıması ile elde edilen XRD pikleri Şekil 1'de sunulmuştur.



Şekil 1. EBİ flaş fırın cürufu X-1şını analizi

XRD grafiğinin tanımlaması ICDD PDF-2 Release 2013 veri tabanı kullanılarak yapılmıştır. Şekil 1 'den görüldügü gibi cürufa ait X-1şını analizinde (XRD) yoğun bir şekilde fayalit piklerinin mevcut olması ve XRF ile varlığı tespit edilen diğer element veya oksitlerin $\left(\mathrm{CaO}, \mathrm{Al}_{2} \mathrm{O}_{3}, \mathrm{ZnO}\right.$ vb.) miktarının azlığı sebebiyle Fayalit (PDF: 00-0441385), Manyetit (PDF: 00-028-0491) ve Silika (PDF: 00-004-0379) dışındaki fazlara ait pikler XRD grafiğinde net olarak gözlenememiştir.

Kolemanit: Çalışma kapsamında yapılan pirometalurjik deneylerde flaks olarak kullanılan 
ve $\mathrm{d}_{100}$ değeri $75 \mu \mathrm{m}$ olan öğütülmüş kolemanit $\left(2 \mathrm{CaO} \cdot 3 \mathrm{~B}_{2} \mathrm{O}_{3} \cdot 5 \mathrm{H}_{2} \mathrm{O}\right)$ Eti Maden İşletmelerinden temin edilmiştir. Kolemanitin ihtiva ettiği kimyasal bağlı suyun deneyler esnasında açığa çıkıp sisteme zarar vermemesi için uzaklaştırılması öngörülmüştür. Yapılan araştırmalar [14] kolemanit içinde bağlı bulunan suyun tamamının $500^{\circ} \mathrm{C}$ civarında yapıdan uzaklaştırılabildiğini ortaya koymuştur. $\mathrm{Bu}$ sebeple öğütülmüş kolemanit 24 saat boyunca belirli aralıklarla karıştırılmak suretiyle kamara tipi bir firın (Protherm 120/10) içinde bekletilerek kristal suyu uçurulmuştur. Kalsine olarak elde edilen kolemanit deneylerde kullanılmak üzere desikatörde muhafaza edilmiştir. Öğütülmüş halde temin edilen kolemanitin ve kalsinasyon sonrası deneylerde kullanılacak hale getirilen kalsine kolemanitin kimyasal analizleri Çizelge 2'de verilmiştir.

Kalsinasyon öncesi \%40 civarında olan $\mathrm{B}_{2} \mathrm{O}_{3}$ oranı kalsinasyon ile $\% 51$ 'in üzerine çıkarılmıştır. Kalsine kolemanit içerisindeki $\mathrm{SiO}_{2}$ ve $\mathrm{CaO}$ miktarları sırasıyla \%7,9 ve \%36,3 olarak tayin edilmiştir. Kalan miktar ise kolemanit minerali içerisinde bulunan diğer oksitlerden $\left(\mathrm{MgO}, \mathrm{Al}_{2} \mathrm{O}_{3}\right.$, $\mathrm{SrO}$ vb.) kaynaklanmaktadır.

Çizelge 2. Öğütülmüş kolemanit ve kalsine kolemanitin kimyasal analizleri

\begin{tabular}{|c|c|c|}
\hline İçerik (\%) & $\begin{array}{l}\text { Öğütülmüş } \\
\text { Kolemanit }\end{array}$ & $\begin{array}{c}\text { Kalsine } \\
\text { Kolemanit }\end{array}$ \\
\hline $\mathrm{B}_{2} \mathrm{O}_{3}$ & $40 \pm 0,5$ & 51,7 \\
\hline $\mathrm{SiO}_{2}$ & $5 \pm 0,5$ & 7,9 \\
\hline $\mathrm{CaO}$ & $27 \pm 1$ & 36,3 \\
\hline Diğer Oksitler & $\sim 6$ & 4,1 \\
\hline Kızdırma Kaybı & $\sim 25$ & - \\
\hline
\end{tabular}

Bu çalışma kapsamında, deneysel işlemler \%99,7 üzerinde $\mathrm{Al}_{2} \mathrm{O}_{3}$ 'e sahip rekristalize alüminadan yapılmış $45 \mathrm{~mm}$ dış çap, $39 \mathrm{~mm}$ iç çap, $100 \mathrm{~mm}$ yükseklik ölçülerine sahip olan Haldenwanger Alsint 99,7 tipi krozelerde gerçekleştirilmiştir. Alumina krozelerdeki deney sonuçlarının karşılaştırıldığı silika krozeler ise toz silika ve kaolinden oluşturulan bulamaçın alçı kalıba dökümü (slip casting) ve sonrasında yüksek sıcaklıkta $\left(1500^{\circ} \mathrm{C}\right)$ pişirilmesi yöntemiyle laboratuvar koşullarında elde edilmiş olup dış çap: $38 \pm 1 \mathrm{~mm}$, iç çap: $30 \pm 1 \mathrm{~mm}$, uzunluk: $80 \pm 2 \mathrm{~mm}$ yaklaşık ölçülerine sahiptir.

\subsection{Deneysel Metot}

Deneysel düzenek: Deneysel çalışmalar, azot gazı atmosferinde gerçekleştirilmiştir. Nem tutucu (silikajel) ve gaz yıkama kolonu $\left(\mathrm{H}_{2} \mathrm{SO}_{4}\right)$ içerisinden geçirilen azot gazı bir gaz akış ölçer yardımıyla belli bir debide dikey tüp firın içerisine gönderilerek azot gazı atmosferi sağlanmaktadır. Deneysel düzeneğe ait şematik gösterim Şekil 2'de verilmiştir.

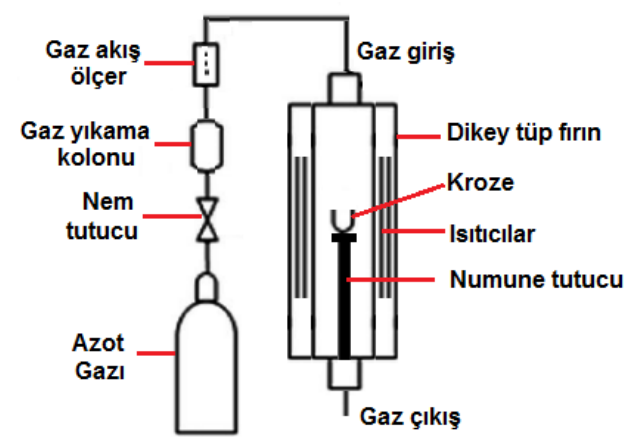

Şekil 2. Çalışmada kullanılan deney düzeneği

$\mathrm{Bu}$ çalışmada, EBİ flaş firın matı ve cürufundan her deney başlangıcında eşit miktarda alınıp deneyin gerçekleştirileceği AK içine konulmuş ve daha önce belirlenen miktardaki kalsine kolemanitten ilave edilerek kroze içerisinde iyice karıștırılmıștır. Burada kullanılan kalsine kolemanitin oranı (\% ağırlıç̧a) mat ve cüruf ağırlıkları toplamı dikkate alınarak hesaplanmıştır. Karışımı içeren kroze ergitmenin yapılacağı dikey fırının daha önce belirlenmiş sicak bölgesine bir maşa yardımıyla indirilmiş ve firının üst kısmındaki silikon tıpa yardımıyla gaz sızdırmazlığı sağlanmıştır. Yeterli miktarda argon gazı gönderilip sistem tamamen temizlendikten sonra argon gazı kapatılıp sisteme yalnızca düşük debide $(\sim 10 \mathrm{ml} / \mathrm{dk}$.) azot gazı gönderilmiştir. $\mathrm{Bu}$ arada isitıcılar devreye alınarak düşük isıtma hızıyla $\left(4^{\circ} \mathrm{C} / \mathrm{dk}\right.$.) firın sicaklığının $1250^{\circ} \mathrm{C}$ olması sağlanmıştır. Deney süresine bağlı olarak firın bu sıcaklıkta bekletilmiş ve yine $4^{\circ} \mathrm{C} / \mathrm{dk}$ hızla yavaş bir şekilde soğuması sağlanmıştır. Yapılan 
deneylerin tamamı aynı şartlar altında (aynı oranda kolemanit ilaveleri, aynı süre, sıcaklık ve atmosfer şartlarında) hem alümina hem de silika krozeler içerisinde gerçekleştirilmiştir.

Soğuması tamamlanan numuneler firın içerisinden çıkarılarak mat ve cüruf örnekleri alınması için krozeden ayırma ve öğütme işlemlerine tabi tutulmuştur. Alınan numuneler $150 \mu \mathrm{m}$ 'nin altına öğütülerek analize gönderilmiştir. $\mathrm{Cu}, \mathrm{SiO}_{2}, \mathrm{Fe}, \mathrm{S}$ ve $\mathrm{B}_{2} \mathrm{O}_{3}$ analizleri ODTÜ Merkezi Laboratuvarında ICP-MS cihazı yardımıyla yapılmıştır. Diğer oksitlerin $\left(\mathrm{CaO}, \mathrm{Al}_{2} \mathrm{O}_{3}, \mathrm{ZnO}\right)$ analizleri ise XRF cihazı ile belirlenmiştir. Ayrıca, cüruflardaki $\mathrm{Cu}$ miktarı EBİ Kimya Laboratuvarında yaş kimyasal metot ile belirlenerek sonuçların tutarlılığı kontrol edilmiştir.

Cüruf viskozitesi ve stvılaşma sıcaklı̆̆ı̆ı hesaplamada kullantlan model: Bir cüruf eriyik sisteminin yüksek sicaklıktaki viskozitesi çeşitli tipteki viskozimetreler kullanılarak deneysel olarak ölçülebilir veya sıcaklık ve kompozisyon değişkenlerine bağlı olarak geliştirilen matematiksel modeller yardımıyla hesaplanabilir [15-17]. Bor içerikli sistemler için yüksek sicaklıklarda cüruf viskozitesini ölçmek oldukça pahalı ve zaman alıcı olmasına karşın, bir matematiksel eşitlik veya yazılım programı yardımıyla cüruf viskozite değerlerini teorik olarak hesaplamak oldukça kolaydır. Araştırmacılar, yüksek sıcaklıklardaki cüruflara ait fizikokimyasal özellikleri (viskozite, sıvılaşma sıcaklığı vb.) belirleyebilmek için cürufun yapısal özelliklerine ve yapılan deneysel sonuçlarına dayanan sıcaklık ve cüruf kompozisyonun etkin olduğu çeşitli tahmin modelleri (Urbain, Riboud, Iida vb.) ortaya sürmüşlerdir. Bu tahmin yöntemleri cüruf bileşimi ve sıcaklık değişkenlerini içeren deneysel, yarıdeneysel veya tamamen matematiksel eşitliklerden oluşabilmektedir. Araştırmacılar tarafindan geliştirilen FactSage [18] termokimyasal yazılım ve veritabanı programı bir cüruf sisteminde var olabilecek birçok oksit için $\left(\mathrm{Al}_{2} \mathrm{O}_{3}-\mathrm{B}_{2} \mathrm{O}_{3}-\mathrm{CaO}\right.$ $\mathrm{FeO}-\mathrm{Fe}_{2} \mathrm{O}_{3}-\mathrm{K}_{2} \mathrm{O}-\mathrm{MgO}-\mathrm{MnO}-\mathrm{Na}_{2} \mathrm{O}-\mathrm{NiO}-\mathrm{PbO}-$ $\mathrm{SiO}_{2}-\mathrm{TiO}_{2}-\mathrm{Ti}_{2} \mathrm{O}_{3}-\mathrm{ZnO}$ ) elde edilmiş deneysel sonuçları kapsadığından birçok termokimyasal hesaplamanın yanı sıra cürufların viskozitelerini tahmin etmek için de kullanılabilecek bir model olarak ortaya çıkmıştır. Bu sebeple, bu çalışma kapsamında elde edilen nihai cürufların viskozite ve sıvılaşma sıcaklığı değerleri FactSage yazılım programı kullanılarak yapılmıştır.

\section{BULGULAR VE TARTIŞMA}

İki ayrı faz oluşturan mat ve cüruf sisteminde silikanın daha fazla ilavesiyle (yani cürufun yapısı silikaya doyma noktasına yaklaşmasıyla) en iyi mat-cüruf ayrımının gözlendiği birçok araştırmacı tarafından vurgulanmıştır [19, 20]. Ancak, erimiş silika üzerinde yapılan çalışmalar silikanın temel yapı taşının $\left(\mathrm{SiO}_{4}\right)^{-4}$ tetrahedral şeklinde olduğunu $\left(\mathrm{Si}^{+4}\right.$ 'ün merkeze yerleştiği ve kovalent bağlara sahip $\mathrm{O}^{-2}$ atomlarının da köşelerde yer aldığı) ve bu sebeple silikatlı cüruflarda tetrahedra yapının üst düzey polimerleşme yaparak $\mathrm{Si}_{2} \mathrm{O}_{7}{ }^{-6}, \mathrm{Si}_{3} \mathrm{O}_{10}{ }^{-8}$ veya $\mathrm{Si}_{4} \mathrm{O}_{13}{ }^{-10}$ gibi yapılar oluşturabileceğini belirtmişlerdir. $\mathrm{Bu}$ polimerleşme beraberinde yüksek viskoz bir yapıyı da getireceğinden $\mathrm{K}_{2} \mathrm{O}$, $\mathrm{Na}_{2} \mathrm{O}, \mathrm{MgO}, \mathrm{CaO}$ ve $\mathrm{ZnO}$ gibi bazı metalik oksitler ilavesiyle silika gruplar arasındaki bağlar kırılarak cürufun viskozitesini düşürmek mümkün olacaktır (Şekil 3). Genellikle bu amaçla ilave edilen kalsiyum oksitin $(\mathrm{CaO})$ ayrıca silis ile birleşip nötr bir cüruf oluşturarak mat-cüruf ayrışmasını kolaylaştırması da hedeflenmektedir. Bunun dışında CaO'in cüruf ergime sıcaklığını bir miktar düşürmeye yönelik etkisi olduğu da bazı araştırmacılar tarafından vurgulanmıştır [21].
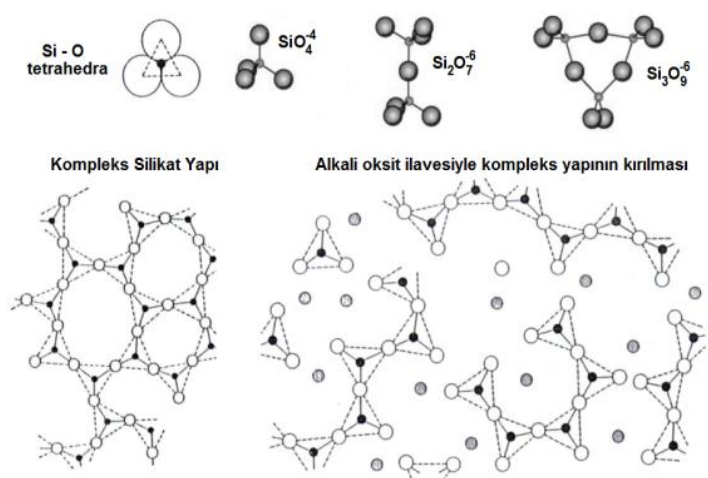

Şekil 3. Si-O tetrahedra yap1, polimerleșme grupları, kompleks silikat yapı ve alkali oksit ilaveleri ile kompleks yapının kır1lmas1 [22] 
Bakır ergitme firınlarında cüruf olușturmak için ilave edilen silikanın gereğinden fazla kullanılması cüruf içerisinde kompleks yapılar oluşturmasına sebep olmakta ve bu durum olası mekaniksel bakır kayıplarını arttırmaktadır. Ancak, bazı alkali oksitlerin ilavesi ile bu kompleks yapıların kırılması mümkün olmaktadır. $\mathrm{Bu}$ noktadan hareketle, Rusen vd. tarafindan yapilan çalışmalarda [3, 7] EBİ'nden temin edilen flaş firın mat1 ve cürufuna belli oranlarda kolemanit $\left(2 \mathrm{CaO} \cdot 3 \mathrm{~B}_{2} \mathrm{O}_{3} \cdot 5 \mathrm{H}_{2} \mathrm{O}\right)$ ilave edilerek kolemanit ilavesinin cürufa giden mekaniksel bakır kayıpları açısından sonuçları irdelenmiştir. Daha önce yapılan bu çalışmalarda araştırmacılar yalnızca silika kroze kullandığından Şekil 4'te verilen $\mathrm{FeO}-\mathrm{SiO}_{2}-\mathrm{Fe}_{2} \mathrm{O}_{3}$ üçlü faz diyagramı üzerinde silikaya doymuş bölge civarındaki bir bileşime sahip cüruf için kolemanit ilavesinin cürufa olan bakır kayıplarını ne yönde etkilediğini ortaya koymuşlardır.

$\mathrm{Bu}$ çalışmada ise, daha düşük silika içerikli (silikaya doymamış) bir cüruf oluşumunda bakır kayıplarının davranışını incelemek için silika içermeyen bir kroze (AK) kullanılarak kolemanit ilavesiyle cürufa olan bakır kayıpları davranışının ortaya çıkarılması amaçlanmıştır. Bu sebeple, flaş firın mat ve cürufu ile $A K$ ve $S K$ içerisinde $N_{2}$ atmosferi altında $1250^{\circ} \mathrm{C}$ ve 2 saat deney şartlarında değişik kalsine kolemanit (\%0, \%2, \%4 ve \%6) ilaveleri yapılarak deneyler gerçekleştirilmiştir. Yapılan deneyler sonucunda elde edilen cüruflara ait kimyasal analizler ve kolemanit ilavesiyle cüruftaki bakır miktarının değişimi Çizelge 3 'te ve Şekil 5 'te verilmiştir.

\section{$\mathrm{FeO}-\mathrm{Fe}_{2} \mathrm{O}_{3}-\mathrm{SiO}_{2}$ \\ $1250^{\circ} \mathrm{C}, 1 \mathrm{~atm}, \mathrm{O}_{2}(\mathrm{~g})$ isobars (atm)}

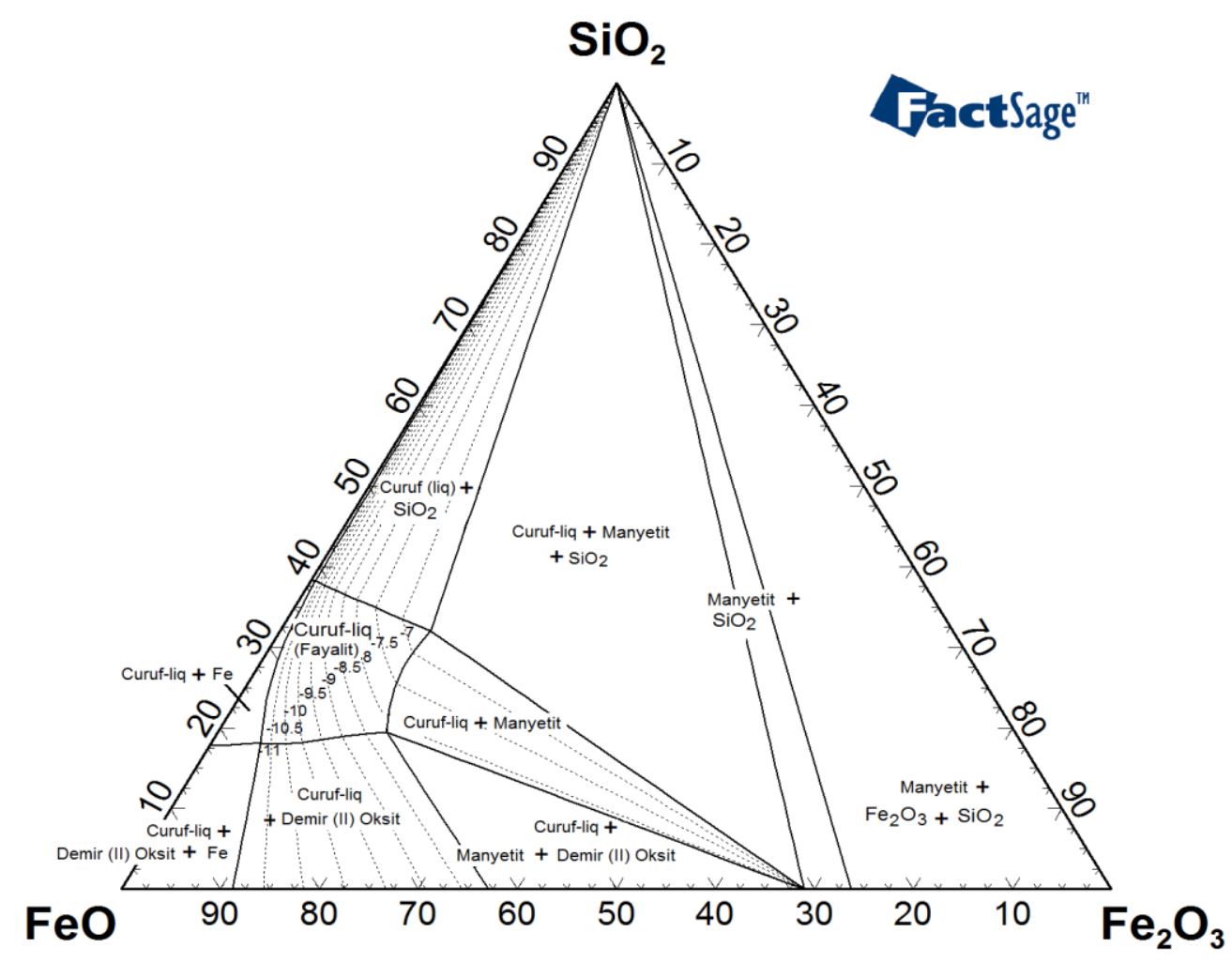

Şekil 4. $\mathrm{FeO}-\mathrm{SiO}_{2}-\mathrm{Fe}_{2} \mathrm{O}_{3}$ üçlü faz diyagramı 
Çizelge 3. Değişik kolemanit ilaveleri ile Alümina kroze (AK) ve Silika kroze (SK) kullanılarak yapılan deneyler sonucunda elde edilen cüruflara ait kimyasal analizler

\begin{tabular}{|c|c|c|c|c|c|c|c|c|c|c|}
\hline $\begin{array}{c}\text { Deney } \\
\text { Kodu }\end{array}$ & $\begin{array}{c}\text { Flaks } \\
(\%)\end{array}$ & $\mathrm{Cu}$ & $\mathrm{SiO}_{2}$ & $\mathrm{Fe}_{3} \mathrm{O}_{4}$ & $\mathrm{FeO}$ & $\mathrm{S}$ & $\mathrm{B}_{2} \mathrm{O}_{3}$ & $\mathrm{Al}_{2} \mathrm{O}_{3}$ & $\mathrm{CaO}$ & $\mathrm{ZnO}$ \\
\hline AK-1 & 0 & 0,69 & 30,8 & 4,3 & 51,7 & 1,2 & -- & 6,2 & 0,9 & 4,1 \\
AK-2 & 2 & 0,55 & 29,9 & 4,2 & 49,8 & 1,2 & 1,5 & 6,8 & 2,0 & 3,9 \\
AK-3 & 4 & 0,43 & 29,8 & 3,7 & 48,9 & 1,2 & 3,2 & 6,3 & 1,9 & 3,9 \\
AK-4 & 6 & 0,38 & 29,5 & 2,9 & 48,5 & 1,1 & 4,6 & 5,8 & 2,1 & 3,8 \\
SK-1 & 0 & 0,55 & 39,3 & 4,3 & 43,6 & 1,0 & -- & 3,7 & 0,9 & 3,7 \\
SK-2 & 2 & 0,31 & 38,6 & 3,7 & 41,3 & 0,8 & 1,6 & 3,9 & 1,9 & 3,5 \\
SK-3 & 4 & 0,29 & 37,3 & 3,1 & 40,9 & 1,1 & 3,1 & 4,1 & 2,7 & 3,4 \\
SK-4 & 6 & 0,28 & 37,2 & 2,4 & 39,4 & 1,0 & 4,4 & 4,3 & 3,2 & 3,3 \\
\hline
\end{tabular}

Tüm bu deneyler sonrasında elde edilen nihai cüruf bileşimleri dikkate alınarak FactSage programı yardımıyla yapılan hesaplamalar hem SK hem de AK kullanımı sonrasında oluşan cürufların ergime (sıvılaşma) sıcaklık değerlerini, ilk çöken malzemenin cinsini ve nihai cürufların viskozite değerlerini ortaya koymaktadır. Nihai cüruflarda ortaya çıkan $\mathrm{FeO} / \mathrm{SiO}_{2}$ oranı ile beraber FactSage programında yapılan hesaplama sonuçları Çizelge 4'te özetlenmiştir.

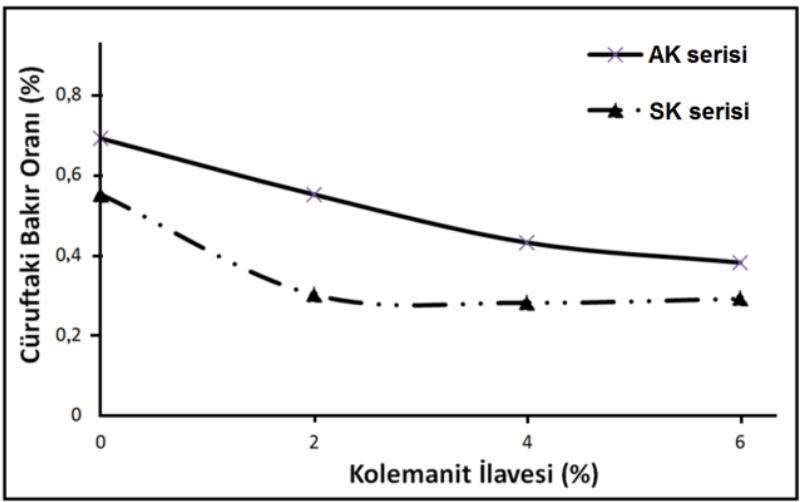

Şekil 5. Değişik kolemanit ilaveleri ile elde edilen cüruflardaki bakır miktarının değişimi

Çizelge 4. FactSage programı ile cürufun viskozite ve sıvılaşma sıcaklığı değerleri ile ilk katılaşan faz hesaplamaları

\begin{tabular}{|c|c|c|c|c|c|}
\hline $\begin{array}{l}\text { Deney } \\
\text { Kodu }\end{array}$ & Flaks (\%) & $\begin{array}{l}\text { Sivılaşma Sicaklığ } 1 \\
\left({ }^{\circ} \mathrm{C}\right)\end{array}$ & İlk Katılaşan Faz & $\begin{array}{l}\text { Viskozite } \\
\text { (Poise) }\end{array}$ & $\begin{array}{c}\mathrm{FeO} / \mathrm{SiO}_{2} \\
\text { oranı }\end{array}$ \\
\hline AK-1 & 0 & 1136,33 & $\mathrm{Fe}_{2} \mathrm{SiO}_{4-\text { fayalit }}$ & 1,58 & 1,68 \\
\hline $\mathrm{AK}-2$ & 2 & 1121,17 & $\mathrm{Fe}_{2} \mathrm{SiO}_{4-\text { fayalit }}$ & 1,77 & 1,66 \\
\hline AK-3 & 4 & 1113,91 & $\mathrm{Fe}_{2} \mathrm{SiO}_{4-\text { fayalit }}$ & 1,97 & 1,64 \\
\hline AK-4 & 6 & 1108,91 & $\mathrm{Fe}_{2} \mathrm{SiO}_{4 \_}$fayalit & 2,07 & 1,64 \\
\hline SK-1 & 0 & 1255,88 & $\mathrm{SiO}_{2 \_}$tridimit & 6,49 & 1,11 \\
\hline SK-2 & 2 & 1199,50 & $\mathrm{SiO}_{2}$ tridimit & 6,32 & 1,07 \\
\hline SK-3 & 4 & 1133,08 & $\mathrm{SiO}_{2}$ tridimit & 5,28 & 1,10 \\
\hline SK-4 & 6 & 1121,92 & $\mathrm{SiO}_{2}$ tridimit & 5,19 & 1,05 \\
\hline
\end{tabular}

Cüruf kompozisyonlarındaki değişimlerin erime sıcaklıkları, viskozite ve yoğunluk gibi cürufun temel bazı özellikleri değiştirdiği birçok araştırmacı [23-26] tarafindan ortaya konmuştur.
$\mathrm{Bu}$ sebeple, her iki tip krozede yapılan deneyler öncelikle içerdikleri kimyasal bileşenler açısından irdelenmelidir. SK ile gerçekleştirilen deneylerin sonuçları Şekil 4'te verilen $\mathrm{FeO}-\mathrm{SiO}_{2}-\mathrm{Fe}_{2} \mathrm{O}_{3}$ üçlü 
faz diyagramı üzerinde gösterildiği gibi silikaya doymuş bölge civarında olacaktır. Ancak, aynı şartlar altında AK ile gerçekleştirilen deney sonuçlarına ait cüruf bileşimlerine bakıldığında, nihai cürufların içeriğindeki silika oranı giderek azalmakta yani nihai cüruf silikaya doymuş bölgeden uzaklaşmaktadır SK ile gerçekleştirilen deneyler sonunda elde edilen cüruflardaki alümina $\left(\mathrm{Al}_{2} \mathrm{O}_{3}\right)$ miktarı başlangıç numunesi olan FFS içindeki $\mathrm{Al}_{2} \mathrm{O}_{3}$ oranı $(\% 3,2)$ ile neredeyse aynı kalmakta iken AK içindeki deneyler esnasında krozeden cürufa alümina geçtiği ve deney sonunda cüruftaki alümina oranının $\% 6$ seviyelerine kadar çıktığı görülmektedir. Ayrıca, deneylere ait kimyasal analiz sonuçlarına bakıldığında $\mathrm{SiO}_{2}$ ve $\mathrm{Al}_{2} \mathrm{O}_{3}$ dışında demir oksit (FeO) miktarının da değişiklik gösterdiği anlaşılmaktadır. SK kullanılarak yapılmış deneylerde \%40 civarında olan $\mathrm{FeO}$ oranı alümina krozede \%50'ye yaklaşmıştır. $\mathrm{Bu}$ durum $\mathrm{FeO} / \mathrm{SiO}_{2}$ oranını önemli ölçüde etkilemiştir. $\mathrm{Bu}$ oranın $\mathrm{SK}$ deneylerinde 1,05-1,11 aralığında iken AK deneylerinde 1,64 1,67 civarına kadar çıktığı Çizelge 4'te açıkça görülmektedir.

Yapılan hesaplamalara bakıldığında (Çizelge 4), SK'de yapılan deneylerde ilk çöken fazın $\mathrm{SiO}_{2}$ olduğu anlaşılmaktadır ki bu da silikaya doymuş çizgi üzerinde (veya yakınlarında) çalışılmış olduğunu göstermektedir. Öte yandan AK'de yapılan çalışmalarda ise cüruf bileşiminin silikaya doymuş bölgeden uzaklaştığı ve $\mathrm{SiO}_{2}$ yerine Fayalit fazının ilk katılaşan faz olduğu anlaşılmaktadır.

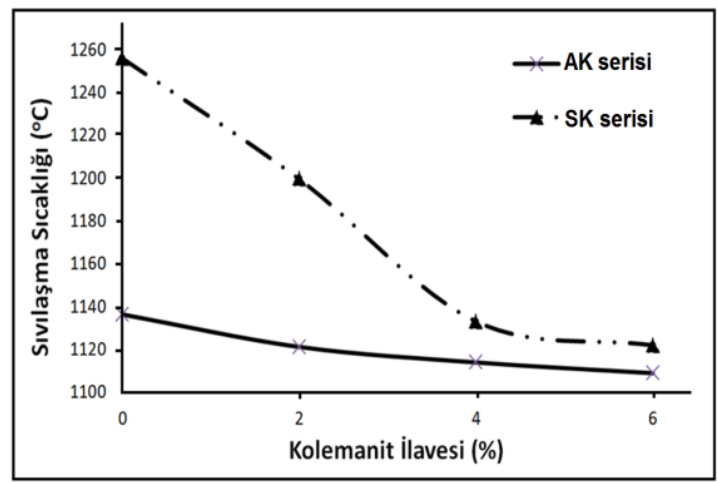

Şekil 6. Değişik kolemanit ilaveleri ile elde edilen cürufların sıvılaşma sıcaklığı değişimleri
Bir diğer önemli husus ise sıvılaşma sıcaklıklarının davranışlarıdır. Farklı miktarda kolemanit ilaveleri ile $\mathrm{AK}$ ve SK kullanılarak yapılan deneylere ait cüruflar için FactSage programı hesaplamalarına göre elde edilen sıvılaşma sıcaklığı değerleri ve viskozite değerleri sırasıyla Şekil 6 ve Şekil 7'de verilmiştir.

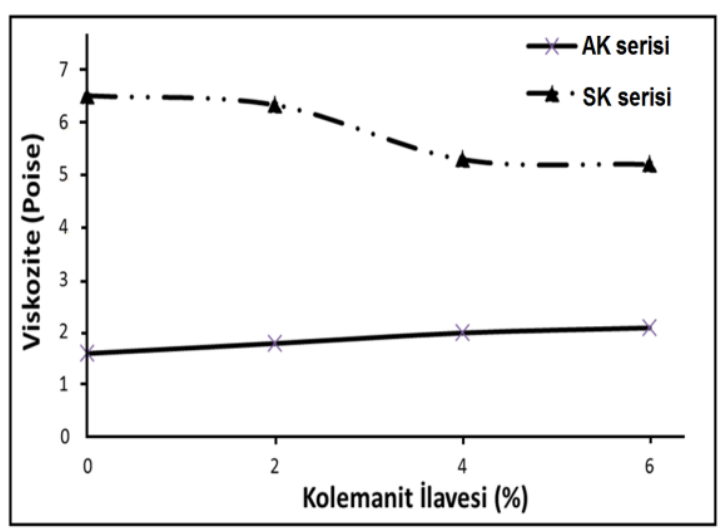

Şekil 7. Değişik kolemanit ilaveleri ile elde edilen cürufların viskozite değişimleri

Şekil 6'da sunulan FactSage programı hesaplamalarına göre, her iki seri için sıvılaşma sıcaklıkları karşılaştırıldığında AK içinde yapılan deneylerde (AK serisi) kolemanit ilavesiyle erime sicaklığ $1136^{\circ} \mathrm{C}$ değerinden $1109^{\circ} \mathrm{C}$ sicaklığına kadar değişim göstermekte iken SK'de yapılan deneylerde (SK serisi) sıvılaşma sıcaklığının 1255 ${ }^{\circ} \mathrm{C}$ 'den başlayıp kolemanit ilavesiyle azalarak 1122 ${ }^{\circ} \mathrm{C}$ değerine kadar gerilediği görülmektedir. Kolemanit ilavesinin yapılmadığ 1 deney sonuçları SK-1 $\left(\mathrm{SiO}_{2}: \% 30,8, \mathrm{FeO}: \% 51,7\right.$ ve $\left.\mathrm{Al}_{2} \mathrm{O}_{3}: \% 6,2\right)$ ile AK-1 $\left(\mathrm{SiO}_{2}: \% 39,3, \mathrm{FeO}: \% 43,6\right.$ ve $\left.\mathrm{Al}_{2} \mathrm{O}_{3}: \% 3,7\right)$ cüruf kompoziyonları açısından karşılaştırıldığında $\mathrm{SiO}_{2}, \mathrm{FeO}$ ve $\mathrm{Al}_{2} \mathrm{O}_{3}$ oranlarının birbirinden oldukça farklı olduğu görülmektedir. Bu sebeple, silikanın daha fazla (veya $\mathrm{FeO} / \mathrm{SiO}_{2}$ oranının daha az) bulunduğu SK serisinde daha yüksek sıvılaşma sıcaklığının ortaya çıkması cürufların kimyasal kompozisyonundaki farklılığına bağlanabilir. Ancak, her iki tip kroze kullanımında da kolemanit ilavesi arttıkça sıvılaşma sıcaklığının azaldığı tespit edilmiştir. Literatürde, sıvılaşma sıcaklığında meydana gelen bu düşüşün sebebi; curufa ilave edilen kolemanitin kimyasal yapısında var olan bor oksit $\left(\mathrm{B}_{2} \mathrm{O}_{3}\right)$ bileşiğinin cüruf 
içerisindeki diğer oksitler ile birleşerek daha düşük erime sıcaklığına sahip ötektik yapılar oluşturması olarak açıklanmaktadır [7, 11-14].

Şekil 7'den görüldüğü üzere, AK serisi cüruflarda ortalama viskozite değeri 2 poise civarında iken SK serisi cüruflarında bu değer 6 poise değerine kadar çıkmaktadır. SK serisi deneyleri sonucunda elde edilen cüruflarda silika içeriğinin fazla olması polimerleşme ile kompleks silika yapılarının meydana gelmesine sebep olmakta ve bu cüruflara ait viskozitelerin AK serisi cüruflarına göre daha yüksek değerlere çıkmasına yol açmaktadır. $\mathrm{FeO} / \mathrm{SiO}_{2}$ oranındaki artışın curufun viskozitesinde belirgin bir azalmaya sebep olduğunu vurgulayan çalışmalar [27, 28] da bu sonuçları destekler niteliktedir.

FactSage programı kullanılarak yapılan viskozite hesaplamalarının doğruluğu daha önce bu konuda yapılmış deneysel ölçümlere dayanan sayısal veriler ile karşılaştırılarak belirlenebilir. Geçmişte bu konuda yapılan araştırmalar [25, 29-32] endüstriyel bakır ergitme cüruflarının $1200-1300^{\circ} \mathrm{C}$ arasındaki viskozite değerlerinin içerdikleri kompozisyona göre (özellikle asit/baz oranına göre) 2-18 poise arasında olduğunu rapor etmişlerdir. Farklı deneysel yöntemlerle elde edilmiş bu değer aralığının bu çalışmada kullanılan FactSage programı ile hesaplanmış viskozite değerleri ile örtüştüğü anlaşılmaktadır.

\section{SONUÇLAR}

Bu çalışmada, başlangıç malzemesi olarak EBİ flaş firın cüruf ve matı alınarak farklı kolemanit ilavelerinin $(\% 0, \% 2, \% 4$ ve \%6) sabit sicaklık $\left(1250^{\circ} \mathrm{C}\right)$ ve sürede (2 saat) farklı kroze tipleri içerisinde ergitilmesi ile cürufa olan bakır kayıplarını ne yönde etkilediği ortaya konmuştur. Böylece, mekaniksel bakır kayıplarını azaltmak için farklı kroze sistemlerinde flaks olarak kolemanit ilavesinin etkisi araştırılmıştır. Elde edilen sayısal değerlere bakıldığında, silika ve alumina kroze kullanımında kolemanit ilavesiyle cürufa olan bakır kayıpları sırasıyla $\% 0,28$ ve $\% 0,38$ değerlerine kadar indirilebildiği görülmüştür.
Elde edilen sonuçlara bakıldığında, farklı kroze kullanımında cürufun farklı sıvılaşma sıcaklıkları gösterdiği ve farklı viskozite değerlerine sahip olduğu anlaşılmaktadır. $\mathrm{Bu}$ farkın cüruf kompozisyonlarındaki $\left(\mathrm{SiO}_{2}, \mathrm{FeO}\right.$ ve $\left.\mathrm{Al}_{2} \mathrm{O}_{3}\right)$ değişiminden kaynaklandığı anlaşılmaktadır.

Bu çalışmada laboratuvar koşullarında elde edilen olumlu sonuçlar, kolemanit mineralinin bakır sektöründe flakslaştırıcı olarak doğrudan kullanımının yaygınlaştırılmasına yönelik umut 1şığı olmaktadır. Mevcut bor ürünlerinden kolemanit için yeni kullanım alanlarının oluşturulmasına yönelik olarak yapılan bu çalışma ile sadece ülkemizde değil dünya genelinde bakır üretimi yapan işletmelerde de bor ürünleri kullanımının artırılması hedeflenmiştir. Böylece, iç tüketime yönelik bor pazarı gelişimi dışında ihracata yönelik yeni alanların oluşturulmasına da katkı sağlanması mümkün olacaktır.

\section{TEŞEKKÜR}

Bu çalışma Karamanoğlu Mehmetbey Üniversitesi Bilimsel Araştırma Koordinatörlüğü tarafından BAP-28-M-16 nolu proje kapsamında desteklenmiştir. Katkıları için teşekkür ederim. Ayrıca, desteklerinden dolayı ODTÜ Metalurji ve Malzeme Mühendisliği Bölümü'ne, Eti Bakır İşletmeleri'ne ve FactSage yazılım programı hesaplamalarında desteğini esirgemeyen Doç. Dr. Bora DERIN'e teşekkür ederim.

\section{KAYNAKLAR}

1. Schlesinger, M. E., King, M. J., Davenport, A. W., Sole, K. C., 2011. Extractive Metallurgy of Copper, $5^{\text {th }}$. edition, Elsevier, Oxford, UK.

2. Gorai, B., Jana R. K., 2003. Characteristics and Utilisation of Copper Slag-a Review, Resources Conservation \& Recycling, 39(4), 299-313.

3. Ruşen, A., Geveci, A., Topkaya, Y. A., Derin, B., 2012. Investigation of Effect of Colemanite Addition on Copper Losses in Matte Smelting Slag, Canadian Metallurgical Quarterly, 51(2), 157-169. 
4. Shen H., Forssberg, E., 2003. An Overview of Recovery of Metals From Slags, Waste Management, 23(10), 933-949.

5. Imris, I., 2003. Copper Losses in Copper Smelting Slags, Metallurgical and Materials Processing: Principles and Technologies (Yazawa International Symposium), 359-373, San Diego.

6. Imris, I., Sánchez, M., Achurra, G., 2005. Copper Losses to Slags Obtained from the El Teniente Process, Mineral Processing Extractive Metallurgy, 114, 135-140.

7. Ruşen, A., Geveci, A., Topkaya, Y. A., Derin, B., 2016. Effects of Some Additives on Copper Losses to Matte Smelting Slag, Journal of Metals, 68(9), 2323-2331.

8. Sridhar, R., Toguri, J. M., Simeonov S., 1997. Copper Losses and Thermodynamic Considerations in Copper Smelting, Metallurgical \& Material Transactions B, 28, 191-200.

9. Toguri J. M., Santander, N. H., 1969. The Solubility of Copper in Fayalite Slags at $1300^{\circ} \mathrm{C}$, Canadian Metallurgical Quarterly, 8(2), 167-174.

10. Chamveha, P., Chaichana, K., Chuachuensuk, A., Authayanun, S., Arpornwichanop, A., 2009. Performance Analysis of a Smelting Reactor for Copper Production Process, Industrial \& Engineering Chemistry Research, $48,1120-1125$.

11. Timucin, M., Sevinc, N., Topkaya, Y. A., Eric, H., 1986. Demir-Çelik üretiminde kolemanit kullanımı, Orta Doğu Teknik Üniversitesi, Araştırma Raporu, Ankara.

12. Ozmen, E., Inger, L., 2006. Colemanite in Steel Production, Sohn International Symposium, 299-306, San Diego.

13. Rüşen, A., Geveci, A., Topkaya, Y. A., 2012. Minimization of Copper Losses to Slag in Matte Smelting by Colemanite Addition, Solid State Sciences, 14(11), 1702-1704.

14. Sivrikaya O., Arol, A. I., 2011. Pelletization of Magnetite Ore with Colemanite Added Organic Binders, Powder Technology, 210, 23-28.

15. Kondratiev, A., Jak, E., Hayes, P. C., 2002. Predicting Slag Viscosities in Metallurgical Systems, Journal of Metals, 54(11), 41-45.
16. Seetharaman, S., Sichen, D., Zhang, Y. J., 1999. The Computer-Based Study of Multicomponent Slag Viscosities, Journal of Metals, 51(8), 38-40.

17. Mills, K. C., Chapman, L., Fox, A. B., Sridhar, S., 2001. 'Round robin' Project on the Estimation of Slag Viscosities, Scandinavian Journal of Metallurgy, 30, 396-403.

18. Fact-Sage, 2016. www.factsage.com

19. Yazawa A., Koh, J., 1974. Thermodynamic Considerations of Copper Smelting, Canadian Metallurgical Quarterly, 13(3), 443-453.

20. Geveci A., Rosenqvist, T., 1973. Equilibrium Relations between Liquid Copper, Iron-Copper Matte and Iron Silicate Slag at $1250{ }^{\circ} \mathrm{C}$, Transtions of the Institution Mining and Metallurgy C, 82, 193-201.

21. See, J. B., Rankin, W. J., 1983. Effect of $\mathrm{Al}_{2} \mathrm{O}_{3}$ and $\mathrm{CaO}$ on Solubility of Copper in SilicaUnsaturated Iron Silicate Slags at $1300^{\circ} \mathrm{C}$, Transtions of the Institution Mining and Metallurgy C, 92, 9-13.

22. Rao, Y.K., 1985. Stoichometry and Thermodynamics of Metallurgical Processes, 1st edition, Cambridge University Press, Cambribge, UK.

23.Zivkovic, Z., Mitevska, N., Mihajlovic, I., Nikolic, D., 2009. The Influence of the Silicate Slag Composition on Copper Losses During Smelting of the Sulfide Concentrates, Journal of Mining and Metallurgy, 45(1), 23-34.

24. Colf V., Howat, D. D., 1979. Viscosities, Electrical Resistivities, and Liquidus Temperatures of Slags in the System CaO$\mathrm{MgO}-\mathrm{Al}_{2} \mathrm{O}_{3}-\mathrm{TiO}_{2}-\mathrm{SiO}_{2}$ under neutral Conditions, Journal South Arfrican Insitute Mining and Metallurgy, 16, 255-264.

25. Aune, R. E., Hayashi, M., Nakajima, K., Seetharaman, S., 2002. Thermophysical Properties of Silicate Slags, Journal of Metals, 54(11), 62-69.

26. Kondratiev, A., Jak, E., 2001. Review of Experimental Data and Modeling of the Viscosities of Fully Liquid Slags in the $\mathrm{Al}_{2} \mathrm{O}_{3}$ $\mathrm{CaO}-{ }^{-} \mathrm{FeO}{ }^{-}-\mathrm{SiO}_{2}$ System, Metallurgical and Materials Transtions B, 32, 1015-1025.

27. Kondratiev, A., Jak, E., 2005. A QuasiChemical Viscosity Model for Fully Liquid Slags in the $\mathrm{Al}_{2} \mathrm{O}_{3}-\mathrm{CaO}-{ }^{-} \mathrm{FeO}$ '- $\mathrm{SiO}_{2}$ System, 
Metallurgical and Materials Transtions B, 36, 623-639.

28. Vadasz P., Tomasek, K., 2009. Contribution to the Study of the Structure of the Melts of the System $\mathrm{FeO}-\mathrm{SiO}_{2}-\mathrm{Fe}_{2} \mathrm{O}_{3}$, Journal of Chemical Engineering Data, 54, 327-332.

29. Vidacak, B., Sichen, D., Seetharaman, S., 2001. An Experimental Study of the Viscosities of $\mathrm{Al}_{2} \mathrm{O}_{3}-\mathrm{CaO}-{ }^{\prime} \mathrm{FeO}$ 'Slags, Metallurgical and Materials Transtions B, 32, 679-684.

30.Zhao, B., Jak, E., Hayes, P. C., 2009. High Temperature Viscosity Measurements for Slags at Controlled Oxygen Potential, VIII International Conference on Molten Slags, Fluxes and Salts, 183-194 Santiago.

31. Forsbacka, L., Holappa, L., Iida, T., Kita, Y., Toda, Y., 2003. Experimental Study of Viscosities of Selected $\mathrm{Al}_{2} \mathrm{O}_{3}-\mathrm{CaO}-\mathrm{MgO}-\mathrm{SiO}_{2}$ Slags and Application of the Iida Model, Scandinavian Journal of Metallurgy, 32, 273-280.

32. Kowalczyk, J., Mroz, W., Warczok, A., Utigard, T. A., 1995. Viscosity of Copper Slags from Chacocite Concentrate Smelting, Metallurgical and Materials Transtions B, 26, 1217-1223. 
